\title{
Influence of the heat loss on the performance of a two-stage gasification reactor
}

\author{
Martino Paolucci, Carlo Borgianni, Sonia Panzieri \\ SEAR sc. Parco Scientifico e Tecnologico di Tor Vergata, \\ Via della ricerca scientifica \\ Roma - Italy
}

\author{
Benedetta de Caprariis, Paolo De Filippis \\ Dept. of Chemical Eng. University of Rome "La Sapienza" \\ Via Eudossiana 18, \\ 00184 Roma - Italy
}

Received: May 22, 2019. Revised: May 28, 2021. Accepted: October 14, 2021. Published: November 15, 2021.

\begin{abstract}
This paper investigates the gasification efficiency of a two stage gasifier, described in all detail in previous works, as a function of the heat loss across the reactor walls. The behaviour of the reactor was simulated using a simple mathematical model already reported in previous papers.
\end{abstract}

The examined heat loss ranges from $0 \%$ of the heat produced by the exothermic reactions into the reactor, up to $20 \%$.

Calculations have been performed by keeping constant both the injected total oxygen and its partition between the two stages, while different feedstocks have been used, such as landfill gas, municipal solid waste (MWS), willow and rice straw.

The results of calculation show that the gasification efficiency at fixed oxygen injection is greatly influenced by the feedstock. The elaboration of the obtained data indicates also that the trend of the gasification efficiency vs. heat loss is a function of the high heating value of the feedstock and of the ratio between the oxygen present into the reactor (injected + the one of the feedstock) and the stoichiometric oxygen necessary to transform the feeding into carbon dioxide and steam.

Keywords - gasifier, two-stage, efficiency, heat loss, walls, syngas

\section{INTRODUCTION}

Gasification is claimed to represent the next evolution in the thermal processing of wastes and residues [1-2]. However, before gasification will became competitive with the more conventional combustion processes it is necessary to develop gasifiers capable to produce a raw syngas sufficiently clean for power generation without the necessity of costly cleaning facilities. To eliminate this drawback and to obtain a sufficiently clean syngas, ready for a further use, a gasifier consisting of two stages in series was developed [3-6]. Although the capability of the developed gasifier to produce a sufficiently clean syngas was tested at lab scale with various wastes, it is necessary to well understand the behaviour of the gasifier under various conditions. In a previous paper [6] it was shown a good agreement between the performed thermodynamic calculations and experimental data in terms of final temperature and chemical composition of the syngas, making the models useful to predict the reactor behavior. On these bases the influence of the feeding HHV (High Heating Value), of the total amount of the injected oxygen and of its partition function (OPR) between stage one and stage two of the reactor was investigated.

Aim of this paper is to make thermodynamic predictions of the influence of the heat loss across the wall of the reactor on the gasifier efficiency by using the mathematical model already reported [4].

\section{MATHEMATICAL MODEL}

The estimation of syngas composition is based on a heat and mass balance carried out taking into account the chemical equilibrium of the water-gas shift and reforming reactions [4]. The model assumes that feedstock and oxygen or an oxygen water mixture are fed into stage one. The products flow into stage two where the model allows an additional injection of oxygen or a steam-oxygen mixture. For examining the influence of the heat loss across the reactor wall on the gasifier efficiency, the heat loss is assumed, for each stage, to be variable from $0 \%$ up to $20 \%$ of the produced heat. It is also assumed that the ash leaves the reactor through a grate at the bottom of stage one at the same temperature of this stage.

\section{FEEDSTOCK AND GASIFIER CHARACTERISTICS}

\section{A. Feedstock}

Municipal solid waste (MSW), willow, landfill gas, and rice straw have been used as feedstock. Table 1 shows their main characteristics. MSW here considered is characteristic of a high income country and it is rich in paper and plastics while the compostable fraction is relatively lower. Reference [7] is the source of the data.

\section{B. Gasifier}

The gasifier, already described in previous works [3-6], consists of two stages placed vertically. Stage one is an updraft reactor where pyrolysis and gasification occur. Tar and gases developed in this stage reach stage two where an additional amount of oxidizing gas is injected. The increased temperature promotes the further gasification of heavy tars and the reforming of light products. In this stage a fixed bed, filled with a first layer of granular alumina and a second layer of $\mathrm{Ni}$ supported catalyst for promoting the reforming reactions, is present. 
TABLE I $\quad$ FEEDSTOCK CHARACTERISTICS

\begin{tabular}{|l|l|l|l|l|}
\hline Characteristics & \multicolumn{1}{|c|}{ MSW } & \multicolumn{1}{|c|}{ Willow } & \multicolumn{1}{|c|}{ Landfill gas } & \multicolumn{1}{|c|}{$\begin{array}{c}\text { Rice } \\
\text { straw }\end{array}$} \\
\hline C \% mass & 47,60 & 49,90 & 47,00 & 38,73 \\
\hline H \% mass & 6,00 & 6,20 & 11,00 & 3,58 \\
\hline N \% mass & 1,20 & 0,40 & - & 0,55 \\
\hline S \% mass & 0,30 & 0,10 & - & 0,06 \\
\hline O \% mass & 32,90 & 41,70 & 53,00 & 36,51 \\
\hline Ash \% mass & 12,00 & 1,70 & 0,00 & 20,57 \\
\hline HHV (MJ/kg) & 19,87 & 18,49 & 28,20 & 14,24 \\
\hline
\end{tabular}

The oxygen content is calculated b difference

\section{RESULTS AND DISCUSSION}

Because the oxidizing gas is injected in both stages, first calculations have been performed by keeping constant the total amount of injected oxygen and its partition ratio between that injected into stage one and the total injected oxygen (oxygen partition ratio, OPR). The injected oxygen was considered to be $0,426 \mathrm{Nm}^{3} / \mathrm{kg}$.

Fig. 1 reports the obtained results. As the figure shows the efficiency of the reactor is greatly influenced by the HHV of the feed, while the heat lost with the ash leaving the reactor has only a negligible effect if compared to the effect of the heat lost across the wall. MSW and willow have, in fact, similar HHV and a large difference in their ash content, but the two curves are quite similar. Fig. 1 shows also that the shape of the curves changes with the feedstock.

The observed drop in the reactor efficiency, shown in the case of MSW and willow, can be explained considering that when the fraction of heat loss is 0,20 , the outlet temperature of the syngas is too low causing an increase of the methane content till about $7 \%$.

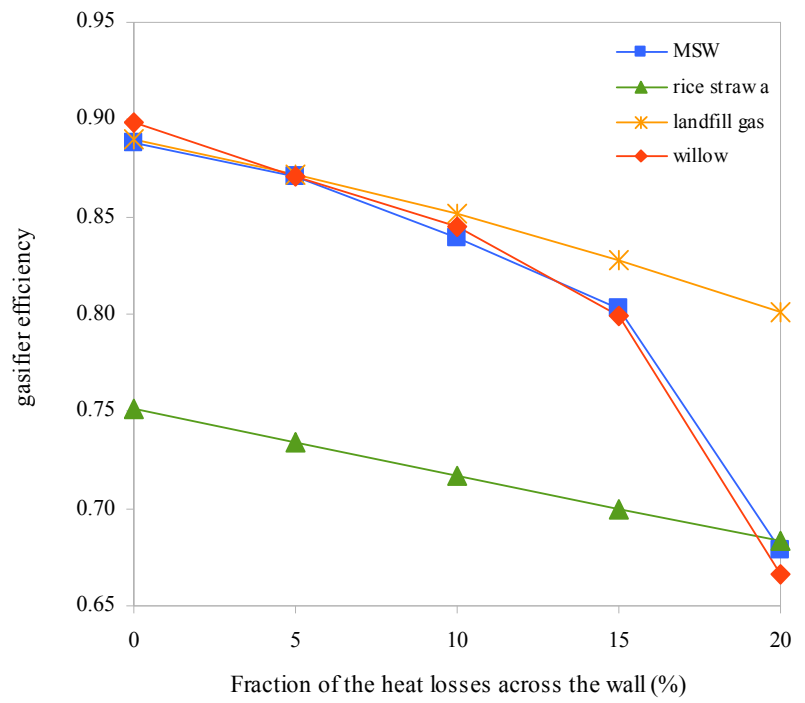

Fig. 1. Relationship between efficiency and heat loss
Different is the case where the fraction of heat loss is 0,10 or lower because the final temperature is higher than $800{ }^{\circ} \mathrm{C}$ and hence the methane content of syngas is greatly reduced. Of course this makes unfavourable the overcoming a heat loss higher than $10 \%$ of the developed heat. The different shape of the reactor efficiency curves among landfill gas, rice straw and MSW, and willow can not be attributed to the HHV only. In fact, even if the rice straw and landfill gas have quite different HHV the behaviour of gasifier efficiency as a function of the heat loss is similar. This behavior can be attributed to a different value of the quantity $Q$ namely the ratio between the oxygen present into the reactor (injected + the one of the feedstock) and the stoichiometric one to transform the feeding into carbon dioxide and steam. To clarify this aspect, new calculations have been performed by keeping constant the feedstock, and hence HHV, and the OPR value and by changing $Q$ from 0,738 down to 0,567 . Rice straw has been selected as a feedstock and four different $\mathrm{Q}$ were utilized.

Fig. 2 shows the results where rice straw a,b,c and $d$ indicated different tests performed at different selected Q i.e. $0,738,0,619,0,591$ and 0,567 As reported in figure the highest efficiency is obtained at the lowest Q namely at 0,567 when the heat loss is lower than $15 \%$

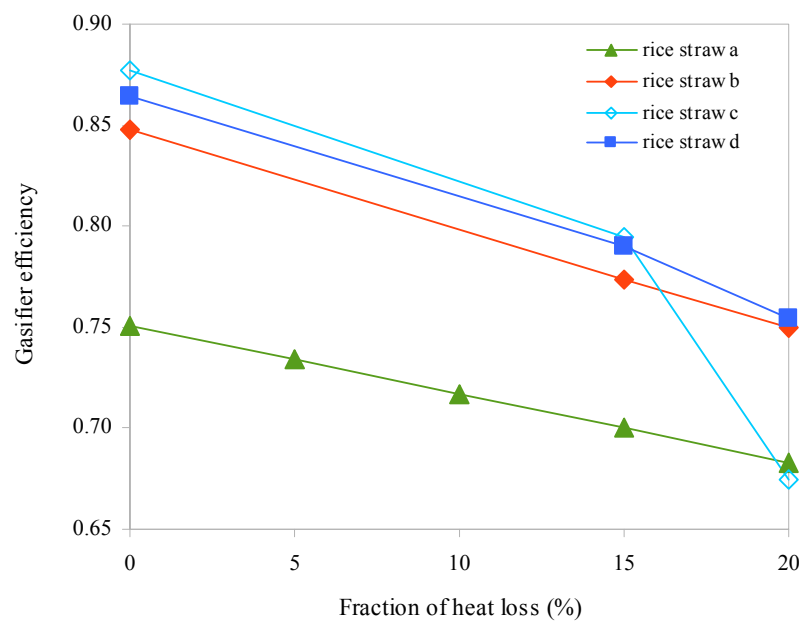

Fig. 2. Effect of Q on the trend of efficiency as a function of heat loss

Decreasing the value of $\mathrm{Q}$, the difference in the reactor efficiency is higher when the heat loss changes from $15 \%$ to $20 \%$ of the developed heat. This change has been defined as "slope".

Fig. 3 reports the trend of this "slope" as a function of Q. The data suggest that this trend can be described by an exponential equation, namely:

$$
\text { slope }=\exp [-(b(Q-a)+c))]
$$

where:

$c$ is a term representing the lowest value of "slope" and cannot be equal to zero

$a$ is a term that depends on the HHV

$b$ is an empirical coefficient 


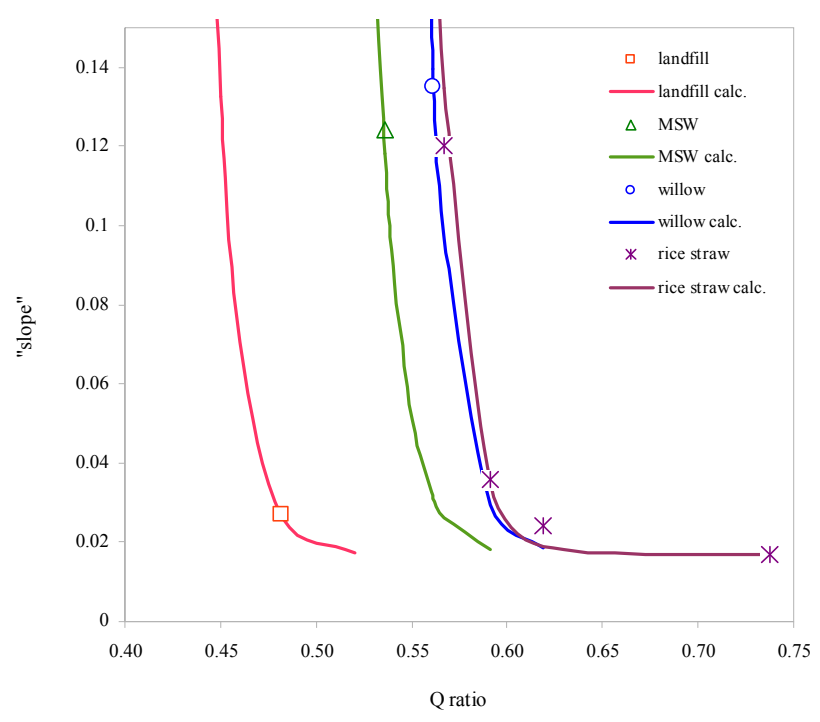

Fig. 3. Trend of "slope" as a function of Q

Both $b$ and $c$ are independent of the HHV and $b$ and a are calculated by the last square analysis in the case of the data related to the rice straw. The data of a, related to the others feedstock, are of course, more approximate. Despite this, it is possible obtain a linear trend between $a$ and HHV with $\mathrm{R}^{2}=$ 0.93, as Fig. 4 shows.

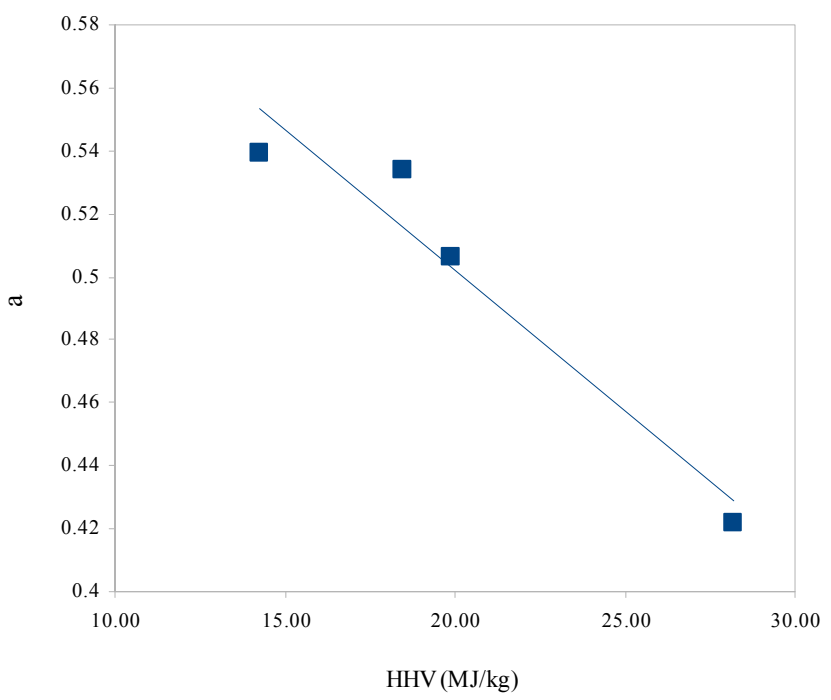

Fig. 4. Constant term $a$, as a function of HHV

The data shown in Fig. 3, 4, which are an elaboration of the results reported in Fig. 2 indicate that the different trends of Fig. 1 are function of Q and HHV. Therefore the shape of Fig. 1 is typical of the selected oxygen injection but it will be different as Q or HHV or both change their value.

\section{CONCLUDING REMARKS}

Data reported in the paper show that the gasification efficiency as a function of the heat loss across the reactor wall at fixed oxygen injection is influenced by the feedstock. In every examined case, to overcome $10 \%$ of the developed heat may be favourable.

The elaboration of the reported data indicates that the different trend of gasification efficiency vs. heat loss can be correlated with the HHV of the feedstock and with the ratio between the oxygen present into the reactor (injected + the one of the feedstock) and the one necessary to transform the feeding into carbon dioxide and steam.

\section{REFERENCES}

[1] Energy from Waste: State-of-the-art-report. $5^{\text {th }}$ Ed. 2006. ISWA Working Group on Thermal Treatment of Waste. Rambøll: Danmark.

[2] T. Malcow, "Novel and innovative pyrolysis and gasification technologies for energy efficient and environmentally sound MSW disposal". Waste management, vol 24, pp 53-79, 2004.

[3] C. Borgianni, P. Defilippis, M. Paolucci, F. Pochetti, "Gasification process of waste containing PVC", Fuel, vol 81, pp. 1827-1833, 2002.

[4] C. Borgianni. P. De Filippis. F. Pochetti. M. Paolucci: "Gasification process of Cuban bagasse in a two-stage reactor" Biomass \& Bioenergy vol. 27, pp. 247-252, 2004.

[5] P. Defilippis, F. Pochetti, C. Borgianni, M. Paolucci, "Automobile shredder residue gasification", Waste Management \& Research vol. 21pp. 459-466, 2003.

[6] P. Defilippis, C. Borgianni, M. Paolucci, F. Pochetti, "Prediction of syngas quality for two-stage gasification of selected waste feedstock", Waste Management, 24, pp. 633-639, 2004

[7] Phyllis Database for biomass and waste. Energy Research Centre of The Netherlands, http://www.ecn.nl/phyllis

\section{Creative Commons Attribution License 4.0 (Attribution 4.0 International, CC BY 4.0)}

This article is published under the terms of the Creative Commons Attribution License 4.0 https://creativecommons.org/licenses/by/4.0/deed.en_US 